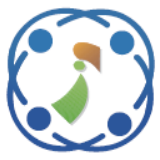

\title{
A Modified Droop Controller for Parallel Operation of Single-Phase Inverters in Islanded Microgrid
}

\author{
Usman Bashir Tayab ${ }^{1 *} \quad$ Muhammad Kashif ${ }^{1,2}$ \\ ${ }^{1}$ University Malaysia Perlis, Perlis, Malaysia \\ ${ }^{2}$ University Malaysia Sarawak, Sarawak, Malaysia \\ * Corresponding author’s Email: usman.tayab@yahoo.com
}

\begin{abstract}
Conventional droop control is a basic control strategy for power sharing in islanded microgrid applications. This strategy has several limitations, such as low transient response, frequency and voltage deviations. This paper presents a modified droop control method for the proper operation of parallel-connected inverters in islanded microgrid. The proposed method is able to improve transient response and achieved higher output power without voltage and frequency deviations by introducing a power derivative term into a conventional droop method. A new method of average power computation is proposed which significantly reduces the delay encountered in conventional approaches and provides the power signal without DC components. The simulation was developed in MATLAB/Simulink to verify the effectiveness of the modified droop control scheme. Based on the results, it can be concluded that the modified droop control strategy improves the performance of parallel-connected power electronic inverters in an islanded microgrid as compared to conventional droop control strategy.
\end{abstract}

Keywords: Active and reactive power, Distributed generation, Droop control, Inverter, Islanded microgrid.

\section{Introduction}

Distributed generation (DG) technology is undergoing rapid development in many countries because of the availability of different energy resources, such as solar panels, batteries, electric vehicles, and wind turbines. DG is usually managed in a decentralized manner through the concept of a microgrid (MG). MG technology offers numerous research possibilities because it is a new and developing technology. An $\mathrm{MG}$ is defined as a cluster of DG units, storage devices, and loads. In practice, MGs are needed to provide sufficient power quality and level to meet consumer demands [1-3]. Power quality is a significant issue because of insufficient or unstable output power from MGs directly affects its performance for short or long periods. In an islanded mode, the MG must maintain the system voltage and frequency; otherwise the variation in the component characteristics of the MG will collapse the system. Harmonic distortion in output power waveform is a serious issue that often occurs as a result of the high-speed operation of inverter switches. In addition, power sharing between the DG units is a critical concern for proper load sharing, especially in renewable energy resources those are not continuously available. The power quality of an MG mainly relies on the active and reactive power regulation because of $\mathrm{MG}$ behaviours, which are mostly influenced by the bulky power distribution system [4-5].

Researchers have proposed different methods such as: the droop, master-slave, and averagecurrent-sharing control methods in order to improve power quality. Among these methods, droop control has gained higher popularity because it is based on the local measured information of the inverter. As it does not require any communication signals between the parallel-connected inverters, it can reduce the line losses in MG. However, the conventional droop control method has several drawbacks such as slow transient response, frequency and voltage deviations which limit the accuracy of power sharing [6]. In previous works 
[7-12], modified droop control techniques were proposed to overcome the abovementioned disadvantages. However, the proposed methods in literature can be further improved for better power sharing and voltage regulation.

In this paper, a modified droop control technique is proposed for accurate power sharing among parallel-connected inverters in islanded MG. The proposed strategy is able to improve the transient response and significantly eliminate the voltage and frequency deviations. The improvement in transient response is achieved by introducing second order generalized integrator with second order low-pass filter based average power computation method. The voltage and frequency deviations are eliminated by integrating a derivative term into the conventional droop control technique.

The remainder of this paper is organized as follows. In Section 2, a brief description of the conventional droop control method is presented. In Section 3, the proposed modified droop control approach is discussed. The detail description of proposed filter for improvement on transient response is provided in Section 4. In Section 5, the design of parallel connected inverter system is discussed. In Section 6, the simulation results of the conventional droop and modified droop control methods are compared. Finally, the conclusion is provided in Section 7.

\section{Conventional Droop Control}

A conventional droop control technique based on frequency and voltage droop was proposed in [13]. An assumption was likewise made that the inverter output impedance is purely inductive because of the high inductive line impedance and the large inductive filter [14].

The block diagram of the conventional droop controller is shown in Fig. 1. The droop characteristic equations can be expressed as:

$$
\begin{aligned}
& \omega=\omega^{\bullet}-m \bar{P}, \\
& E=E^{\bullet}-n \bar{Q},
\end{aligned}
$$

where $\bar{P}, \bar{Q}, m$, and $n$ are the average active output power, average reactive output power, frequency droop constant, and voltage droop constant of the inverter, respectively; $\omega^{\bullet}$ is the rated frequency; and $E^{\bullet}$ is the rate-voltage amplitude.

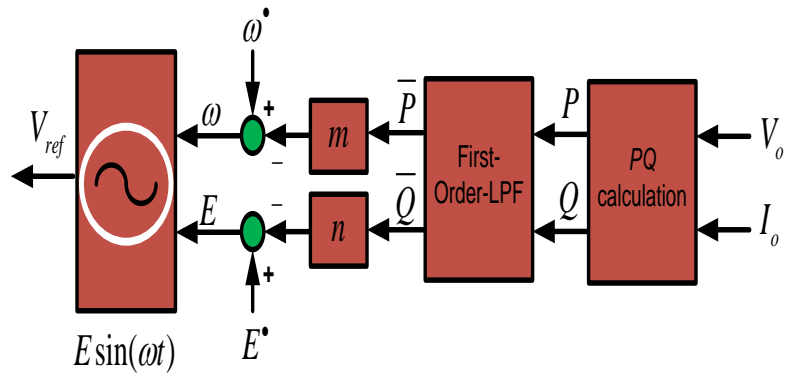

Figure.1 Block diagram of conventional droop control technique.

The average active and reactive output power can be calculate using Eq. (3) and (4).

$$
\begin{aligned}
& \bar{P}=\left(\frac{\omega_{c}}{s+\omega_{c}}\right) \cdot P, \\
& \bar{Q}=\left(\frac{\omega_{c}}{s+\omega_{c}}\right) \cdot Q,
\end{aligned}
$$

The main advantage of the droop control technique is that it can avoid critical communication links among parallel-connected inverters. The absence of communication links between parallel-connected inverters provides significant flexibility and high reliability [13]. However, the conventional droop technique has several drawbacks [9-14], such as the following:

$>$ Slow transient response.

$>$ Voltage and frequency deviations.

$>$ Inherent trade-off between voltage regulation and load sharing.

$>$ Poor harmonic load sharing between parallelconnected inverters in the case of non-linear loads.

$>$ Line impedance mismatch between parallelconnected inverters that affect active and reactive power sharing.

$>$ Poor performance with renewable energy resource.

\section{Proposed Modified Droop Control}

The structure of the modified droop control method is shown in Fig. 2. The average active and reactive output powers can be taken by multiplying the output voltage by the output current and filtering the product using a second-order general integrator scheme with second-order low-pass filter (SOGISecond-order-LPF) as following: 


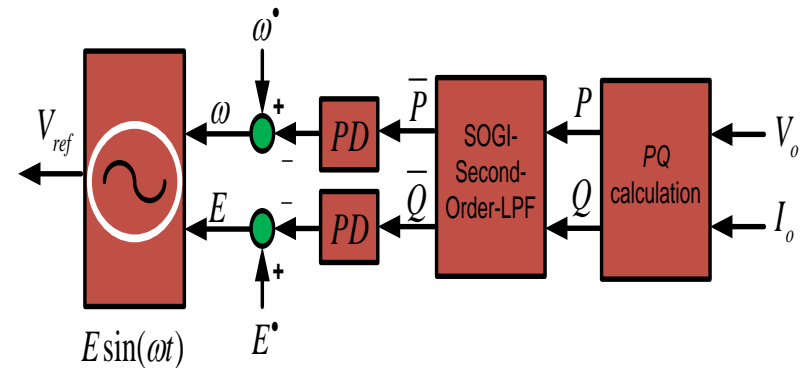

Figure.2 Modified droop control method.

$$
\begin{aligned}
& \bar{P}=\left[\left(\frac{2 \varsigma \omega_{f} s}{s^{2}+2 \varsigma \omega_{f} s+\omega_{f}^{2}}\right) \cdot\left(\frac{\omega_{n}}{s^{2}+2 \varsigma \omega_{n} s+\omega_{n}^{2}}\right)\right] \cdot P, \\
& \bar{Q}=\left[\left(\frac{2 \varsigma \omega_{f} s}{s^{2}+2 \varsigma \omega_{f} s+\omega_{f}^{2}}\right) \cdot\left(\frac{\omega_{n}}{s^{2}+2 \varsigma \omega_{n} s+\omega_{n}^{2}}\right)\right] \cdot Q,
\end{aligned}
$$

Here, $\omega_{f}, \omega_{n}$ and $\zeta$ are the filter resonant frequency, filter nature oscillation frequency, and damping factor, respectively. The modified droop control equations can be written as follows:

$$
\begin{aligned}
& \omega=\omega^{\bullet}-m \bar{P}-m_{d} \frac{d \bar{P}}{d t}, \\
& E=E^{\bullet}-n \bar{Q}-n_{d} \frac{d \bar{Q}}{d t},
\end{aligned}
$$

where $\bar{P}, \bar{Q}, m, m_{d}, n$, and $n_{d}$ are the average active output power, average reactive output power, frequency droop coefficient, frequency droop derivative, voltage droop coefficient, and voltage droop derivative of the inverter, respectively; $\omega^{\bullet}$ is the rated frequency; and $E^{\bullet}$ is the rate-voltage amplitude.

\section{Proposed Filter for Improvement in Transient Response}

To calculate the average value of inverter output instantaneous active and reactive power is one of the most important parameters in droop control strategies. The inverter instantaneous output power contains a frequency ripples and DC components. According to instantaneous power theory, the active instantaneous power is the product of inverter output voltage and current and average active power is calculated by filtering the instantaneous active power.

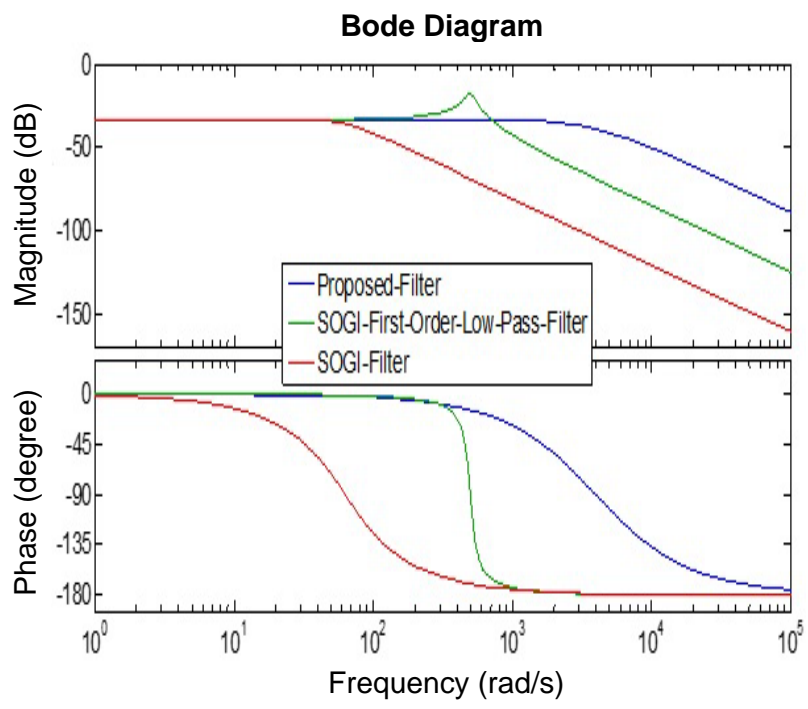

Figure.3 Comparison between proposed filter, SOGIfirst-order-LPF and SOGI filter.

Similarly, the average reactive power is obtained. However, in this case, the inverter output voltage should have ninety-degree phase lag. Conventionally, the first order low pass filter (LPF) is used to obtain the average value of active and reactive power. However, the higher filter time constant has to be chosen in order to gain better filtering performance. But the transient response of system becomes slow due to large value of filter time constant. SOGI with first order low pass filter is used to improve the transient response by different group of researchers [15]. However, it can be improved further more. Therefore, in this research work, a novel filter has been proposed to obtain the average active and reactive power. This novel filter is a combination of second order low pass filter and SOGI filter which can achieve desired transient response. The characteristics of the proposed filter can be represented by Eq. (9) and Fig. 3 shows the frequency domain behaviour of the proposed filter through a Bode diagram.

$G_{\text {filter }}=\left(\frac{2 \varsigma \omega_{f} s}{s^{2}+2 \varsigma \omega_{f} s+\omega_{f}^{2}}\right) \cdot\left(\frac{\omega_{n}}{s^{2}+2 \varsigma \omega_{n} s+\omega_{n}^{2}}\right)$,

\section{Design of Parallel Operation System}

The inverter acts as an interface between the DG unit, load, and power grid. Inverters are used in parallel to a $\mathrm{MG}$ to improve performance. Parallel operation of inverters has several advantages such as high reliability, flexibility and easy expansion 
because the remaining modules can still deliver the required power to the load in case an inverter failure [16].

The operational block diagram of two parallel connected inverters without communication link in islanded MG is shown in Fig. 4. This parallel connected inverter system consists of two feedback control loop i.e., power sharing control and voltage control loop. The modified droop control method is used to achieve the accurate power sharing between the two parallel connected inverters. The modified droop controller of each inverter obtains the output active and reactive power of that specific inverter and varies the amplitude and frequency of the reference voltage based on the droop constants. The new reference voltage will be given as a set point to the voltage controller of each inverter. Droop control techniques reduce the output impedance, which is advantageous for parallel operation.
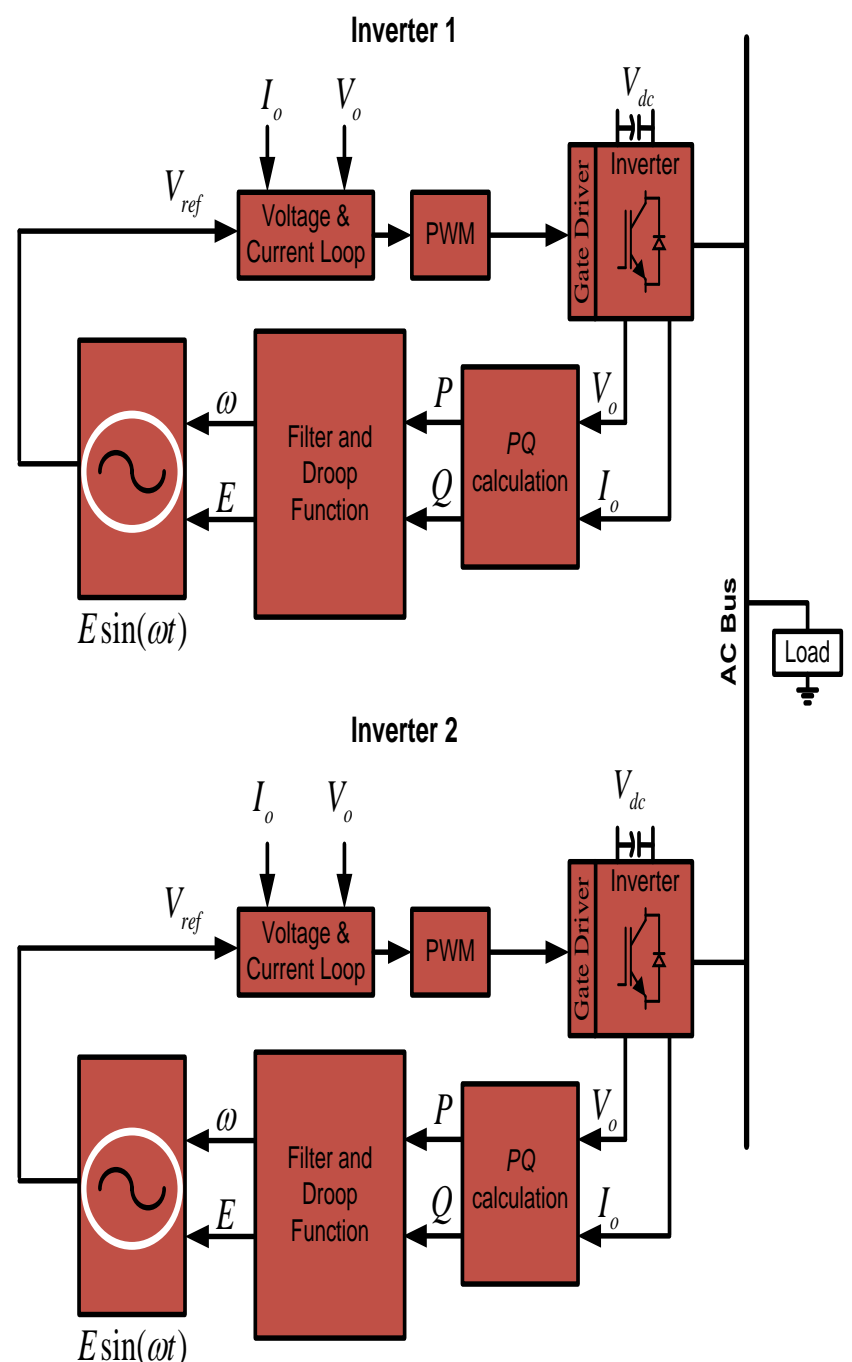

Figure.4 Parallel connected inverters in Islanded MG.

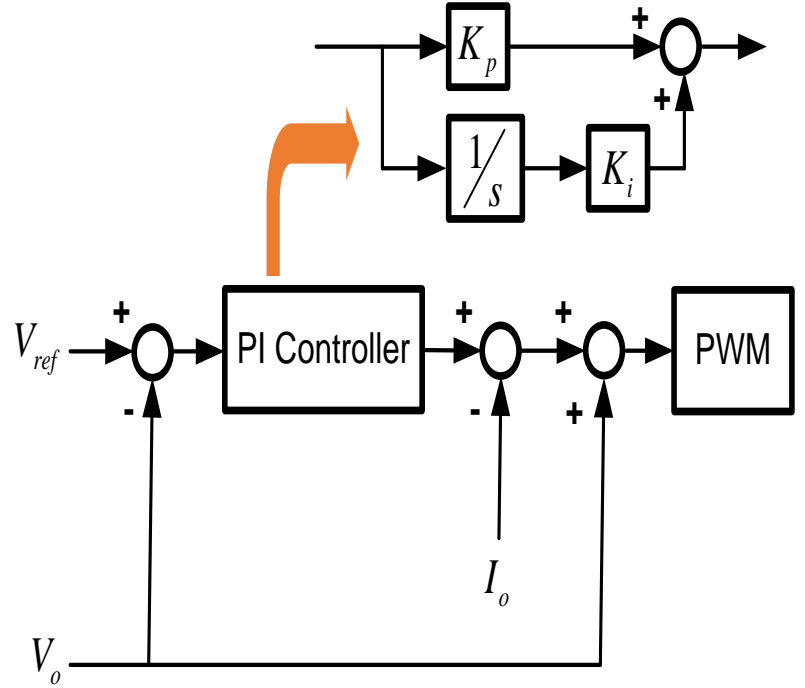

Figure.5 Voltage and current control loop.

The voltage and current control loop is shown in Fig. 5 and PI controller is utilized for controlling the output voltage of inverter. The load block is composed of inductive load.

\section{Simulation Results and Discussion}

In this section, the proposed modified droop control and conventional droop control methods are simulated with two 5KVA inverters connected in parallel to verify the validity of the proposed modified droop control technique. The simulations are divided into different cases and presented in subsection 6.1 and 6.2. The system parameters considered for the simulation are as follows: $\mathrm{L}=1 \mathrm{mH}, \mathrm{C}=20 \mu \mathrm{F}, V_{\text {in }}=220 \mathrm{~V}, Z_{1}=0.12+\mathrm{j} 0.028$, and $Z_{2}=0.12+\mathrm{j} 0.028$. The rated voltage and system frequency are $110 \mathrm{~V}$ RMS and $50 \mathrm{~Hz}$ respectively. The droop coefficients are listed in Table 1.

Table 1. Droop coefficients

\begin{tabular}{|c|c|c|}
\hline Parameters & Symbol & Values \\
\hline \multicolumn{3}{|c|}{$\begin{array}{c}\text { Conventional Droop Control } \\
\end{array}$} \\
\hline$P-\omega$ droop & $m_{1}$ and $m_{2}$ & $\begin{array}{l}0.00015 \\
\mathrm{rad} / \mathrm{W} . \mathrm{s}\end{array}$ \\
\hline$Q-E$ droop & $n_{1}$ and $n_{2}$ & $\begin{array}{l}0.0016 \\
\text { V/Var }\end{array}$ \\
\hline \multicolumn{3}{|c|}{ Modified Droop Control } \\
\hline $\begin{array}{c}P-\omega \text { droop } \\
\text { (Proportional) }\end{array}$ & $m_{1}$ and $m_{2}$ & $\begin{array}{l}0.00015 \\
\mathrm{rad} / \mathrm{W} . \mathrm{s}\end{array}$ \\
\hline $\begin{array}{c}P-\omega \text { droop } \\
\text { (Derivative) }\end{array}$ & $m_{d 1}$ and $m_{d 2}$ & $\begin{array}{l}6 \times 10^{-7} \\
\mathrm{rad} / \mathrm{W} . \mathrm{s}\end{array}$ \\
\hline $\begin{array}{c}Q-E \text { droop } \\
\text { (Proportional) }\end{array}$ & $n_{1}$ and $n_{2}$ & $\begin{array}{c}0.000004 \\
\text { V.s/VAr }\end{array}$ \\
\hline $\begin{array}{c}Q-E \text { droop } \\
\text { (Derivative) }\end{array}$ & $n_{d 1}$ and $n_{d 2}$ & $\begin{array}{l}6 \times 10^{-7} \\
\text { V.s/VAr }\end{array}$ \\
\hline
\end{tabular}




\subsection{Case 1: Comparison Between Modified Droop Control and Conventional Droop Control Under Fixed Load Condition}

In this case, the simulation has been performed with fixed inductive load. The start-up waveforms of the active and reactive powers of the two inverters are shown in Figs. 6 and 7. These waveforms were obtained by using the conventional droop and proposed modified droop control methods. It is revealed from the comparison result that the proposed modified droop control method provides higher active and reactive powers compared with the conventional droop method. Moreover, the proposed method modified the transient response significantly as seen from Figs. 6 and 7. The frequency restoration and start-up waveform of the voltage are shown in Figs. 8 and 9. Figs. 8 and 9 also show that the frequency and voltage deviations are lower in the proposed modified droop control method than those of the conventional droop control method. Hence it is obvious that the modified droop control method shows batter performance under fixed load condition.

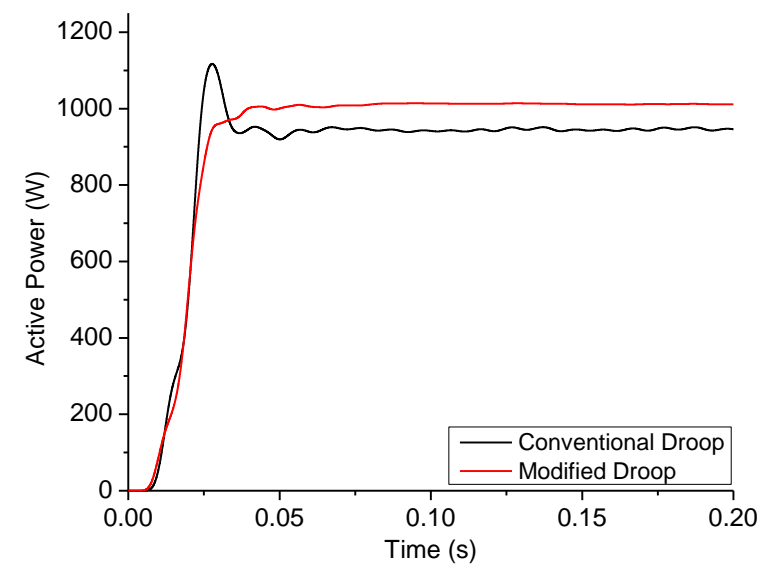

Figure.6 Start-up waveforms of active power of both inverters.

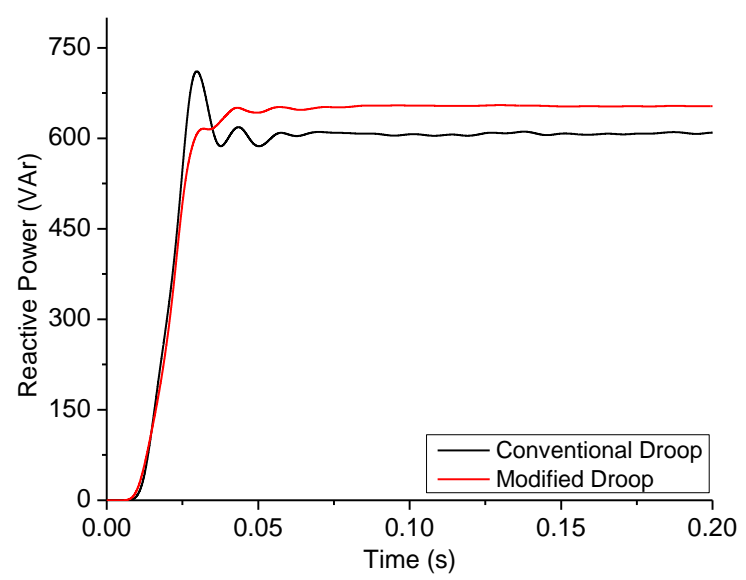

Figure.7 Start-up waveforms of reactive power of both inverters.

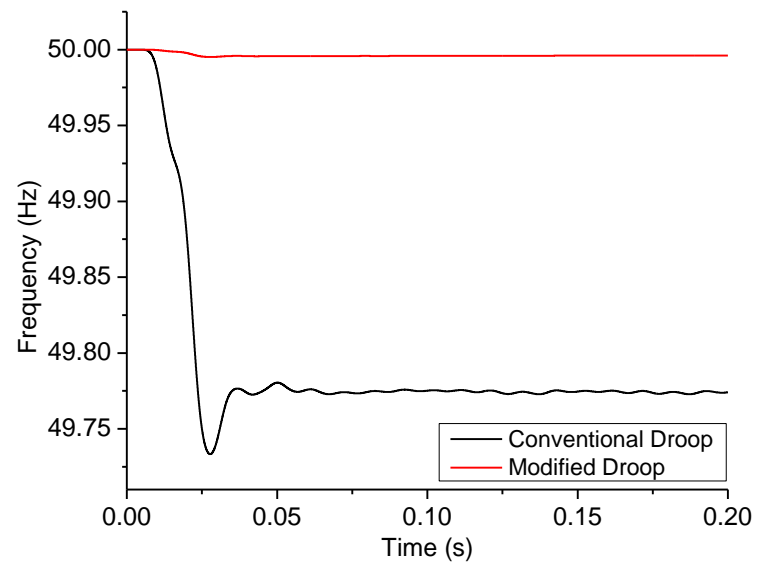

Figure.8 Frequency of both inverters at start-up.

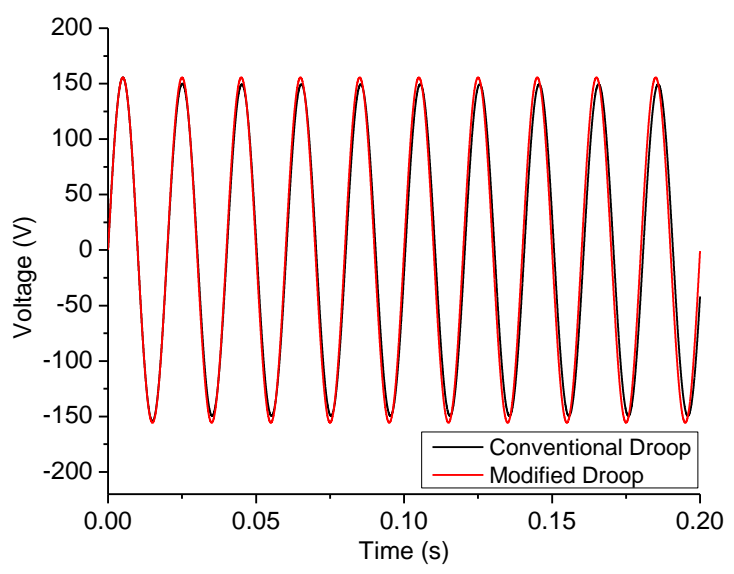

Figure.9 Voltage of both inverters at start-up.

\subsection{Case 2: Comparison Between Modified Droop Control and Conventional Droop Control Under Load Changing Condition}

In this section, the simulation results of modified droop control and conventional droop control method under load changing condition are compared. To achieve the load changing condition, an additional inductive load is connected at $0.14 \mathrm{~s}$ and disconnected at $0.24 \mathrm{~s}$ while one inductive load remains connected all the time. Figs. 10 and 11 show the waveform of active and reactive output power of both inverters during change of load. The waveforms indicate that the modified droop control has the lowest oscillation during change of load as compared to conventional droop control which indicates that the desired or better transient response has been achieved through modified droop control technique. In addition, the modified droop control technique also provides higher power during load changing condition.

The voltage output waveform and frequency restoration of both inverters during load change are shown in Figs. 12 and 13 respectively. It is obvious that the control method causes voltage and 
frequency deviations due to additional load. However, the voltage and frequency deviations during load changing by modified method are lower than those of conventional method. Hence it can be concluded that the modified droop control method shows better performance under variable load conditions.

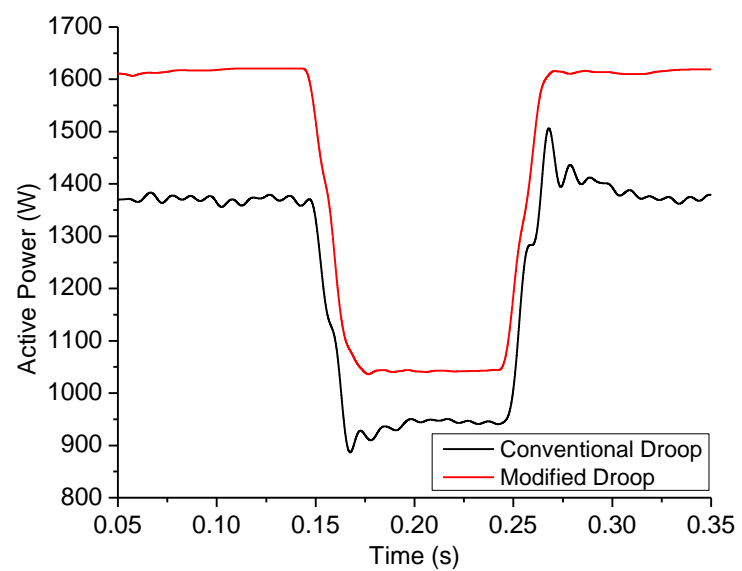

Figure.10 Active power of both inverters during load change.

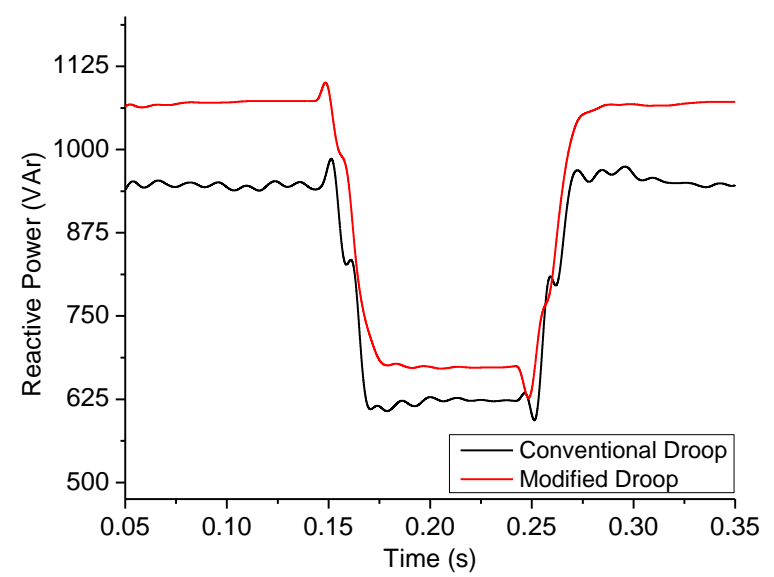

Figure.11 Reactive power of both inverters during load change.

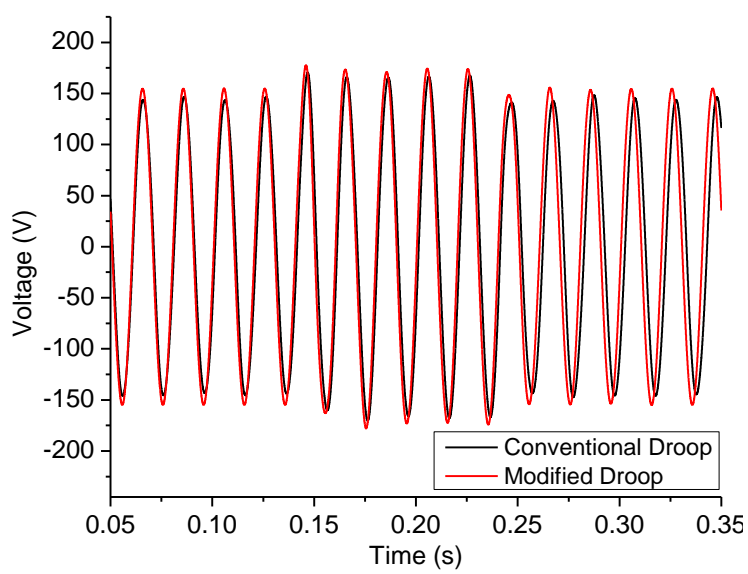

Figure.12 Voltage of both inverters during load change.
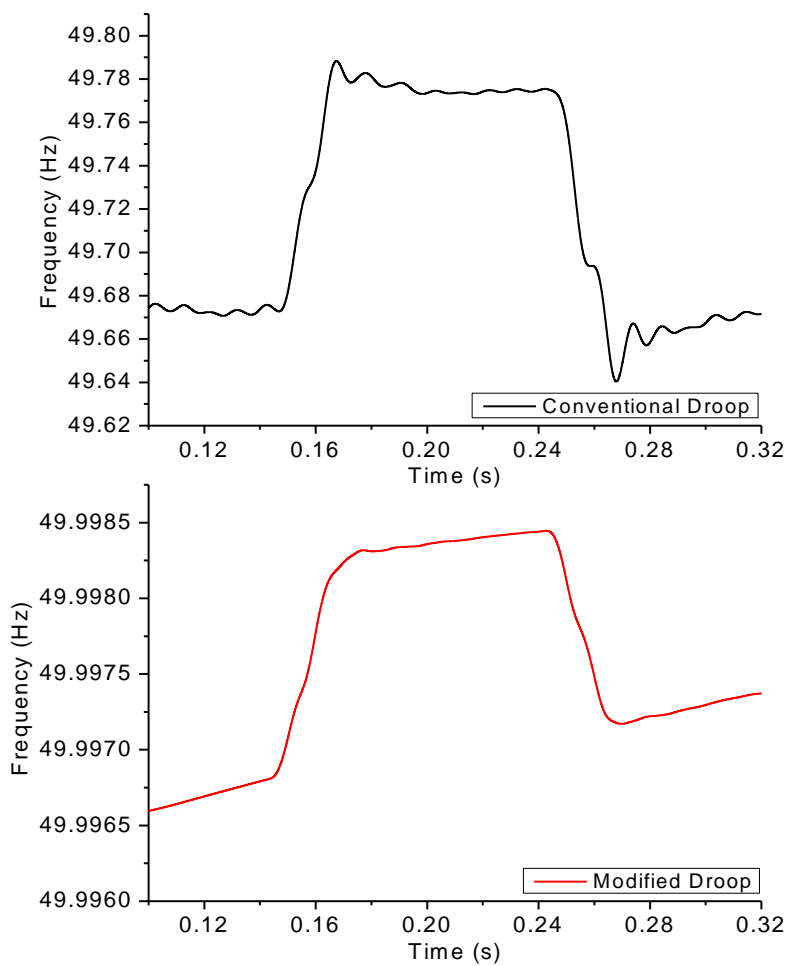

Figure.13 Frequency of both inverters during load change.

\section{Conclusion}

A modified power sharing control strategy for parallel-connected inverters has been presented in this paper. Based on the droop control technique, the controller avoids the use of communication signals between DG units. In a clear-cut contract with the conventional droop control strategy, the proposed controller is able to significantly improve the transient response of parallel-connected inverters system in islanded MG during fixed and variable balance load conditions. Furthermore, the proposed controller significantly reduces the voltage and frequency deviations during both load conditions. Simulation results show the efficacy of the proposed modified droop control over the conventional droop control method. However, the performance of the proposed controller can be improved further in future. Thus, it is planned to enhance the performance of modified droop control method by adding a control loop to properly share the voltage and current harmonic. The presented control strategy also planned to implement for parallel operation of three phase inverters in islanded and grid-connected MG. In addition, the proposed controller will be modified for power sharing during unbalance load and line impedance mismatch condition. 


\section{Acknowledgments}

Author would like to thankfully acknowledge the financial support by University Malaysia Perlis for this research work.

\section{References}

[1]I.Y. Chung, W. Liu, D.A. Cartes, E.G. Collins, and S.I. Moon, "Control Methods of InverterInterfaced Distributed Generators in a Microgrid System", IEEE Transactions on Industrial Applications, Vol.46, pp.1078-1088, 2010.

[2]H. Mahmood, D. Michaelson, and J. Jiang, "Reactive Power Sharing in Islanded Microgrids Using Adaptive Voltage Droop Control", IEEE Transactions on Smart Grid, Vol.6, pp.30523060, 2015.

[3]M.I. Azim, M.J. Hossain, and H.R. Pota, "Design of a controller for active power sharing in a highly-resistive microgrid", IFAC-Papers-OnLine. Vol.48, pp.288-293, 2015.

[4]J.C. Vasquez, R.A. Mastromauro, J.M. Guerrero, and M. Liserre, "Voltage Support Provided by a Droop-Controlled Multifunctional Inverter", IEEE Transactions on Industrial Electronic, Vol.56, pp.4510-4519, 2009.

[5]S.J. Ahn, J.W. Park, I.Y. Chung, S.I. Moon, S.H. Kang, S.R. Nam, "Power-Sharing Method of Multiple Distributed Generators Considering Control Modes and Configurations of a Microgrid", IEEE Transactions on Power Delivery, Vol.25, pp.2007-2016, 2010.

[6]J. Heand, and Y.W. Li, "An Enhanced Microgrid Load Demand Sharing Strategy", IEEE Transactions on Power Electronic, Vol.27, pp.3984-3995, 2012.

[7]E. Barklund, N. Pogaku, M. Prodanovic, C.H. Aramburo, and T.C. Green, "Energy Management in Autonomous Microgrid Using Stability-Constrained Droop Control of Inverters", IEEE Transactions on Power Electronic, Vol.23, pp.2346-2352, 2008.

[8]Y.W. Li, and C.N. Kao, "An Accurate Power Control Strategy for Power-ElectronicsInterfaced Distributed Generation Units Operating in a Low-Voltage Multibus Microgrid", IEEE Transactions on Power Electronic, Vol.24, pp.2977-2988, 2009.

[9]J.M. Guerrero, L.G. Vicuna, J. Matas, M. Castilla, and J. Miret, "A Wireless Controller to Enhance Dynamic Performance of Parallel Inverters in Distributed Generation Systems", IEEE Transactions on Power Electronic, Vol.19, pp.1205-1213, 2004.
[10]L. Zheng, C. Zhuang, J. Zhang, and X. Du, “An Enhanced Droop Control Scheme for Islanded Microgrids", International Journal of Control \& Automation, Vol.8, pp.63-74, 2015.

[11]H. Zhang, S. Kim, Q. Sun, and J. Zhou, "Distributed Adaptive Virtual Impedance Control for Accurate Reactive Power Sharing Based on Consensus Control in Microgrids", IEEE Transactions on Smart Grid, Vol.99, pp.113, 2016.

[12]Q.C. Zhong, "Robust Droop Controller for Accurate Proportional Load Sharing Among Inverters Operated in Parallel", IEEE Transactions on Industrial Electronic, Vol.60, pp.1281-1290, 2013.

[13]G.C. Konstantopoulos, Q.C. Zhong, B. Ren, and M. Krstic, "Bounded Droop Controller for Parallel Operation of Inverters", Automatica, Vol.53, pp.320-328, 2015.

[14]Q.C. Zhong, and Y. Zeng, "Universal Droop Control of Inverters with Different Types of Output Impedance", IEEE Access, Vol.4, pp.702-712, 2016.

[15]S. Tolani, and P. Sensarma, "An Improved Droop Controller for Parallel Operation of Single-Phase Inverters Using R-C Output Impedance", In Proc. of IEEE Int. Conf. Power Electron. Drives \& Energy Syst., India, pp.1-6, 2012.

[16]A. Mohd, E. Ortjohann, D. Morton, and O. Omari, "Review of control techniques for inverters parallel operation", Electric Power System Research, Vol.80, pp.1477-1487, 2010. 